\title{
CES
}

COOPERATIVISMO E ECONOMÍA SOCIAL

Núm. 41 (2018-2019), páxs. 175-192

ISSN: 1130-2682

\section{AS ASSOCIAÇÕES MUTUALISTAS E O VOTO POR CORRESPONDÊNCIA - COMENTÁRIO AO ACÓRDÃO \\ DO TRIBUNAL DA RELAÇÃO DE LISBOA DE 19- \\ 4-2018 (PROCESSO N 11266/16.4T8LSB-6)}

\section{MUTUAL ASSOCIATIONS AND THE POSTAL VOTE - COMMENT ON THE JUDGMENT OF TRIBUNAL DA RELAÇÃO DE LISBOA OF 19-4-2018 (PROCESS NUMBER 11266/16.54T8LSB-6)}

\section{Mafalda Miranda Barbosa*}

Recepción: 12/7/2019 - Aceptación: 6/10/2019

Professora Auxiliar da Faculdade de Direito da Universidade de Coimbra. Pátio da Universidade, 3004-528 Coimbra; mcnmb@fd.uc.pt 


\section{RESUMO}

Em face do artigo $72^{\circ}$ do CAM, que dispunha que, "salvo se os estatutos dispuserem de outra forma, é admitido o voto por correspondência, sob condição de o seu sentido ser expressamente indicado em relação ao ponto ou pontos da ordem de trabalhos e a assinatura do associado se encontrar reconhecida notarialmente", colocou-se a questão de saber se a expressão "salvo se os estatutos dispuserem de outra forma" se refere apenas à admissibilidade de voto por correspondência ou também à sua permissão em condições diferentes das previstas na lei, designadamente quando não haja reconhecimento notarial das assinaturas. Nas páginas que se seguem, refletiremos sobre essa questão - que entretanto parece ter sido também resolvida pelo artigo $86^{\circ}$ do novo Código das Associações Mutualistas -, tendo como ponto de partida o caso decidido pelo Tribunal da Relação de Lisboa, no acórdão de 194-2018 (Processo no 11266/16.4T8LSB-6).

Palavras-Chave: associações mutualistas; voto por correspondência; liberdade de associação; liberdade estatutária

\section{ABSTRACT}

Article 72 of Mutualist Association Code establishes that "unless otherwise is provided in the statutes of the mutual association, voting by correspondence is allowed, provided that its meaning is expressly indicated in relation to the item or items on the agenda and the signature of the member is recognized/certified by a notary". Taking this article in consideration we may ask as to whether the expression" unless otherwise is provided in in the statutes of the mutual association" refers only to the admissibility of voting by correspondence or also to its permission under other conditions than those provided by law, in particular when there is no recognition of signatures by a notary. In this paper, we will reflect on this issue, which in the meantime seems to have also been solved by Article 86 of the new Code of Mutualist Associations, taking in consideration the case decided by the Lisbon Court of Appeal in its judgment of 19-4 -2018 (Case No. 11666 / 16.4T8LSB-6).

KEYWORDS: mutual associations; postal vote; freedom of association; statutory freedom. 
SUMÁRIO: 1. O CASO DECIDIDO PELO TRIBUNAL DA RELAÇÃO DE LISBOA. 2. A SOLUÇÃO DO TRIBUNAL DA RELAÇÃO DE LISBOA E OS ARGUMENTOS MOBILIZADOS. 3. AS ASSOCIAÇÕES MUTUALISTAS E A FORMULAÇÃO DO PROBLEMA. ORDEM DE SEQUÊNCIA. 4. A INTERPRETAÇÃO JURÍDICA COMO UM PROBLEMA NORMATIVO. A INTERPRETAÇÃO DA NORMA NA SUA REMISSÃO PARA OS PRINCÍPIOS: A LIBERDADE ASSOCIATIVA. 5. A INTERPRETAÇÃO COMO UM PROBLEMA NORMATIVO (CONT.): A INTERPRETAÇÃO DOGMÁTICA E TELEOLÓGICA E O RECURSO AOS DADOS SISTEMÁTICOS - O REGIME DAS SOCIEDADES E DAS ASSOCIAÇÕES. 6. O NOVO CÓDIGO DAS ASSOCIAÇÕES MUTUALISTAS E O REFORÇO DA POSIÇÃO SUSTENTADA. 7. CONCLUSÃO. 8. BIBLIOGRAFIA.

CONTENTS: 1. THE CASE DECIDED BY THE LISBON COURT OF APPEAL. 2. THE DECISION OF THE LISBON COURT OF APPEAL AND THE ARGUMENTS DEVELOPED. 3. THE MUTUAL ASSOCIATIONS AND THE JURIDICAL PROBLEM. 4. JURIDICAL INTERPRETATION AS A NORMATIVE PROBLEM. THE INTERPRETATION OF THE RULE AND THE REFERENCE TO THE PRINCIPLES: FREEDOM OF ASSOCIATION. 5. JURIDICAL INTERPRETATION AS A NORMATIVE PROBLEM (CONT.): DOGMATIC INTERPRETATION AND PURPOSIVE INTERPRETATION AND THE REFERENCE TO THE JURIDICAL SYSTEM - CORPORATE DISCIPLINE AND ASSOCIATION DISCIPLINE. 6. THE NEW CODE OF MUTUAL ASSOCIATIONS AND THE REINFORCEMENT OF THE POSITION HELD. 7. CONCLUSION. 8. LITERATURE.

\section{O caso decidido pelo Tribunal da Relação de Lisboa}

$\mathrm{O}$ caso decidido pelo Tribunal da Relação de Lisboa, no Acórdão de 19 de Abril de 2018 (Processo nº11266/16.4T8LSB-6, relatora Maria de Deus Correia ${ }^{1}$ ) pode contar-se em poucas palavras: A e B propuseram uma ação declarativa contra o Montepio Geral - Associação Mutualista, pedindo a anulação da deliberação da Assembleia Geral realizada em Dezembro de 2015, que homologou os resultados eleitorais para os seus órgãos associativos. Para tanto alegaram que, no decurso do ato eleitoral, que tinha tido lugar em 2 de Dezembro de 2015, se tinham verificado procedimentos violadores das normas estatutárias da ré. Esta, por seu turno, contrapôs que o processo eleitoral se tinha pautado pelo rigor e independência, tendo assegurado a todas as listas concorrentes condições de igualdade para a divulgação dos seus projetos e para a participação no ato. A ação foi julgada improcedente. Foi, então, interposto recurso.

Neste recurso, foi alegado que o método de votação por correspondência, previsto no artigo $44^{\circ} / 3$ e 4 dos Estatutos do Montepio, sem reconhecimento presencial das assinaturas, viola o disposto no artigo $72^{\circ} / 2$ Código das Associações Mutualis-

\footnotetext{
1 In www.dgsi.pt
}

Cooperativismo e Economía Social (CES). N. ․ 41. Curso 2018-2019. Páxs. 175-192. ISSN: 1130-2682 
tas (CAM). De acordo com posição defendida pelos recorrentes, a expressão "salvo se os estatutos dispuserem em contrário" apenas se reporta à proibição de voto por correspondência, e não à sua admissibilidade em condições diferentes das previstas na lei, donde se violaria, assim, com o citado preceito dos Estatutos o disposto nos artigos $72^{\circ} / 2 \mathrm{CAM}$ e $177^{\circ} \mathrm{CCiv}$., devendo, nessa medida, ser anulada a deliberação da assembleia geral que declarou uma dada lista como vencedora das eleições.

Para além de questões relativas à matéria de facto (tanto quanto esta se possa cindir, metodologicamente, da matéria de direito), o Tribunal da Relação de Lisboa foi, portanto, chamado a pronunciar-se acerca da interpretação do artigo $72^{\circ} / 2$ CAM e, designadamente, acerca da sua natureza dispositiva ou imperativa.

O artigo 44\% 3 dos Estatutos do Montepio estatui que é permitido o voto por correspondência, desde que cumpridos determinados requisitos: estar a lista dobrada em quatro, com os nomes votados para dentro, e contida em sobrescrito individual fechado; constar do referido sobrescrito o nome, o número e a assinatura do associado; e endereçado ao presidente da Mesa da Assembleia Geral. No voto por correspondência, nos termos do $\mathrm{n}^{\circ} 4$ do mesmo artigo, "a assinatura do associado deve ser conferida com o espécime existente no Montepio Geral, devendo o voto ser registado nas listas de presença e introduzido na urna".

Por seu turno, o artigo $72^{\circ}$ do CAM dispunha que, "salvo se os estatutos dispuserem de outra forma, é admitido o voto por correspondência, sob condição de o seu sentido ser expressamente indicado em relação ao ponto ou pontos da ordem de trabalhos e a assinatura do associado se encontrar reconhecida notarialmente".

O busílis da questão está, pois, na interpretação do âmbito e do alcance do segmento "salvo se os estatutos dispuserem de outra forma".

Importa, contudo, notar que a norma em questão deixou, entretanto, de vigorar: o novo Código das Associações Mutualistas disciplina a matéria do voto dos associados em Assembleia Geral no artigo 86 ${ }^{\circ}$, cuja formulação, sendo próxima do anterior regime, dela difere em termos essenciais para a resolução do problema que aqui releva. Poderiam, nesse sentido, suscitar-se dúvidas acerca do problema da sucessão da lei no tempo. Contudo, sem razão: na verdade, o novo Código das Associações Mutualistas, aprovado pelo DL n 59/2018, de 2 de Agosto, entrou em vigor trinta dias após a sua publicação. Ora, sendo o recurso proferido em 19 de Abril de 2018, perde sentido equacionar a sua aplicabilidade ao caso sub iudi$c e$. O que não significa que a nova disciplina não deva ser tida em conta como auxiliar interpretativo, tanto quanto os princípios mutualistas continuem inalterados.

\section{A solução do Tribunal da RelaÇão de Lisboa E OS ARGUMENTOS MOBILIZADOS}

O Tribunal da Relação de Lisboa considerou que a expressão "salvo se os estatutos dispuserem de outra forma" abrange não só a possibilidade de voto por 
correspondência, como também a necessidade de reconhecimento notarial da assinatura dos votantes, por ser essa a interpretação que melhor se coaduna com os objetivos constantes do Preâmbulo do Código das Associações Mutualistas, onde se pode ler que, "através de uma maior flexibilização da legislação estatutária - e de uma certa ideia de desregulamentação, valoriza-se a liberdade e autonomia da organização e do funcionamento das associações mutualistas, com a correlativa responsabilização acrescida dos seus órgãos associativos". A norma tem, segundo a posição expendida no acórdão, natureza claramente supletiva, sendo apenas aplicável caso os estatutos da associação nada dispuserem sobre a matéria. Nessa medida, confirma a decisão recorrida.

A priori, podemos adiantar que a posição do Tribunal da Relação de Lisboa nos parece acertada. Contudo, cremos que, para a sustentar, podem ser mobilizados outros argumentos para além daqueles que foram aduzidos pelo coletivo de juízes.

\section{As ASSOCIAÇÕES MUTUALISTAS E A FORMULAÇÃO DO PROBLEMA. ORDEM DE SEQUÊNCIA}

As associações mutualistas são, de acordo com o artigo 1\%1 CAM, pessoas coletivas de direito privado, de natureza associativa, com um número ilimitado de associados, fundos patrimoniais variáveis e duração indefinida que, essencialmente, através da entreajuda e da quotização dos seus associados, praticam, no interesse destes e das suas famílias e em obediência aos princípios mutualistas, fins de auxílio recíproco de proteção social e desenvolvimento humano.

Enquanto associações que são, regem-se, em tudo o que não esteja previsto em legislação específica, pelo regime legal das associações, sendo-lhes aplicáveis os artigos $167^{\circ}$ e seguintes do CCiv.

Significa isto, desde logo, que, para além dos princípios mutualistas por que se regem - entre os quais destacamos, pela importância que podem ter na argumentação subsequente, os princípios da autonomia e da democraticidade, o primeiro a implicar que as associações mutualistas são independentes, na sua gestão e funcionamento, em relação ao Estado e outras entidades públicas, sem prejuízo do exercício da tutela, da supervisão ou do licenciamento de atividades e equipamentos; e o segundo a determinar que o funcionamento dos órgãos das associações mutualistas e a eleição dos respetivos membros se regem por princípios e métodos democráticos, segundo o processo estabelecido nos seus estatutos -, são igualmente mobilizáveis os princípios norteadores da constituição e funcionamento das associações, em geral. Aí é de ter em conta o princípio da liberdade de associação como refração a este nível do princípio da autonomia privada, de que aqueles princípios específicos, aliás, não são mais do que emanação particular. 
Compreende-se, por isso, que muitas das normas que disciplinam as associações mutualistas não sejam imperativas, sendo frequentes as remissões para os estatutos. É exatamente a isso que assistimos no artigo $72^{\circ}$ do anterior CAM. Nenhuma dúvida se levanta, portanto, quanto à possibilidade de os estatutos preverem o voto por correspondência. A referida disciplina - anteriormente vigente - consagrava-o expressamente. $\mathrm{O}$ que se torna duvidoso é se a supletividade abrange não só a possibilidade de voto por correspondência, como também a necessidade de reconhecimento notarial da assinatura dos votantes.

Para tanto, é necessário interpretarmos a norma. Simplesmente, para que possamos lograr obter uma resposta normativamente fundada e materialmente justa, não é possível olharmos para aquela como um texto. A tentativa de captação da mesma como um simples enunciado linguístico coloca-nos diante da aporia, pois que a formulação do legislador pode, em termos literais, tanto apontar para a prescindibilidade, prevista nos estatutos, do reconhecimento notarial da assinatura dos votantes, como para a solução inversa.

Importa, por isso, começar por recordar algumas ideias chave em matéria de interpretação jurídica para, depois, as aplicar ao caso concreto, convocando para o efeito quer os princípios norteadores das associações mutualistas, quer a intencionalidade do ordenamento jurídico no tocante às pessoas coletivas. Com isto avançaremos alguns argumentos que nos permitem sustentar uma posição que, avant la lettre, nos parece clara e que coincide com aquela que foi consagrada no acórdão ora em comentário.

\section{A INTERPRETAÇÃO JURÍDICA COMO UM PROBLEMA NORMATIVO. A INTERPRETAÇÃO DA NORMA NA SUA REMISSÃO PARA OS PRINCÍPIOS: A LIBERDADE ASSOCIATIVA}

Tradicionalmente, a interpretação jurídica era entendida como um problema hermenêutico. A norma seria encarada em abstrato, no jogo entre letra e espírito. Aquela definiria um círculo de sentidos possíveis e fixaria as fronteiras dentro das quais o espírito se poderia mover, excluindo os chamados candidatos negativos, ou seja, os sentidos que a letra inequivocamente e a priori excluiria. Mas dentro desse círculo de sentidos possíveis, tal letra voltaria a atuar na sua função de seleção positiva, dicotomizando os candidatos positivos - os sentidos naturais, aqueles que mais correspondessem aos usos habituais das expressões em causa - e os candidatos neutros - aqueles que correspondessem a utilizações menos habituais dos elementos linguísticos ${ }^{2}$.

\footnotetext{
2 Sobre o problema da interpretação, para mais desenvolvimentos, cf. A. Castanheira Neves, «Interpretação Jurídica», Digesta, vol. II, Coimbra Editora, Coimbra, 1995, págs. 337 s.; A. CASTANHEIRA NeVES, $O$ actual problema metodológico da interpretação jurídica, I, Coimbra Editora, Coimbra, 2003; J. Pinto Bronze, Lições de Introdução ao Direito, Coimbra Editora, Coimbra, 2002,
} 
Só depois entrariam em jogo os outros elementos da interpretação, o elemento sistemático, histórico e teleológico, obtendo-se, assim, o resultado interpretativo devido, que se traduziria numa interpretação declarativa, restritiva ou extensiva ${ }^{3}$, distinguindo-se claramente da analogia. Na verdade, esta só seria chamada a operar quando se ultrapassassem os sentidos pré-jurídicos delineados pela letra da lei.

Ora, é esta visão do problema da interpretação que se afigura metodologicamente insustentável. A consideração atomista da norma, nas duas grandezas que a compõem, só é possível se aceitarmos que o valor linguístico de um texto é constante e que a utilização de expressões comuns num enunciado jurídico deixa inalterado o seu sentido. Ora, qualquer um destes pressupostos é falso. O sentido de qualquer comunicação está sempre dependente do interlocutor, do contexto e do momento histórico em que se situa. Da mesma forma, o uso de expressões linguísticas num texto jurídico altera o sentido das mesmas ${ }^{4}$. Pelo que teremos de concluir, oportunamente, que, abstratamente, a norma nada nos comunica, só sendo possível interpretá-la no confronto com o caso concreto. Por isso, o objeto da interpretação passa a ser a norma problema, isto é, ela deixa de ser vista como um enunciado linguístico para passar a ser entendida como a tipificação de um problema, com uma intrínseca intencionalidade problemática. Em confronto ficam, então, dois problemas e o nosso raciocínio passa a caminhar do particular para o particular, razão pela qual se pode afirmar que a analogia estará sempre presente em qualquer processo de interpretação jurídica ${ }^{5}$. Deixa de fazer sentido falar de interpretação extensiva e restritiva, passando a assumir-se como resultados interpretativos a extensão e a redução teleológica, formas de interpretação corretiva que não nos apartam da analogia ${ }^{6}$.

Não basta, porém, que a norma seja transcendida pelas exigências do caso concreto: haverá de ser, igualmente, remetida para os princípios normativos em que se

págs. 809 s.; Mafalda Miranda Barbosa/João Pedro Rodrigues, «Da incompetência do TC para apreciar eventuais violações do princípio da legalidade criminal: breve reposicionamento crítico em sede metodológica», Estudos em homenagem ao Prof. Doutor António Castanheira Neves, vol. III, Coimbra Editora, Coimbra, 2008, págs. 108 s. (que aqui damos por reproduzido em alguns pontos específicos).

3 Se ambos os elementos da norma coincidissem, a interpretação dir-se-ia declarativa. Se a letra fosse mais ampla que o espírito, restringir-se-ia o sentido textual para o fazer coincidir com o seu espírito, dando-se lugar à interpretação restritiva. Se, pelo contrário, a letra fosse menos ampla que o espírito, alargar-se-ia o sentido textual da lei, dentro dos seus sentidos possíveis, para o fazer coincidir com o seu espírito, abrindo-se as portas a uma interpretação extensiva.

\section{J.Pinto Bronze, Lições de Introdução ao Direito, pág. 894}

5 Sobre o ponto, cf., novamente, Mafalda Miranda Barbosa/João Pedro Rodrigues, «Da incompetência do TC», págs. 108-109 e, para desenvolvimentos não consentâneos com o nosso âmbito de análise, a demais bibliografia já citada acerca da interpretação jurídica.

6 Cf. A. Castanheira Neves, Metodologia Jurídica - Problemas fundamentais, Coimbra Editora, Coimbra, 1993, pág. 242. 
louva, sob pena de incompreendermos a sua intencionalidade normativa. De facto, a analogia de que falamos, quando devidamente entendida, não se pode confundir com a mera identidade dos termos. Estivéssemos nós no campo matemático e ela transverter-se-ia em pura identidade ${ }^{7}$; no campo do direito, temos toda a barreira entre o geral e abstrato da norma e o particular e concreto do caso a cavar um fosso que exige, para o juízo de similitude suficiente que se procura, a convocação de um tertium datum que o viabilize ${ }^{8}$. Donde a interpretação da norma (entendida em termos amplos) implicará não só a remissão do critério para o caso que o convoca, como para os princípios normativos do sistema, que, em rigor, são fundamentais para se poder compreender o sentido normativo dessa mesma norma.

Os dados metodológicos que recordamos afiguram-se fundamentais para compreendermos que a adequada solução do problema considerado no acórdão do Tribunal da Relação de Lisboa que comentamos não pode quedar-se no puro pla-

7 Cf. A. Castanheira Neves, Metodologia Jurídica, pág. 242.

8 Cf. A. Castanheira Neves, Metodologia Jurídica, págs. $256 \mathrm{~s}$.

Castanheira Neves fala da analogia como uma "integrante e unitária inteligibilidade ou racionalização", que implica a verificação de três características fundamentais: “1) (...) essas entidades não veem reduzida pela analogia a sua diversidade $(\ldots) ; 2)(\ldots)$ a inteligível integração deverá ser uma conclusão nivelada (...) i.é, deverá manter-se no mesmo nível dos relata e não passar (...) a um nível diverso (..); 3) (...) exige-se um fundamento específico da integração (fundamentum relationis, tertium comparationis) a justificar a inteligibilidade ou racionalidade dessa unificante associação na diferença". (cf. Metodologia Jurídica, 241).

Ora, esse fundamentum relationis não pode deixar de ser encontrado na expressão do próprio direito. Sem que com isto resvalemos para o vício, contaminador do pensamento de raiz tradicional denunciado pelo jurista, que redundaria, afinal, na mutação do nível de grau entre os relata, ao admitir a analogia iuris, entendida como a analogia entre o caso concreto e um princípio geral extraído de um conjunto de normas. Pois que, não só os princípios a que apelamos em nada se confundem com esses princípios gerais de índole normativista, como a justificação da relação por aquele tertium comparationis não implica a passagem do particular ao geral (cf. A. Castanheira Neves, Metodologia Jurídica, págs. 244-254).

Em rigor, Castanheira Neves chama-nos a atenção para a índole argumentativa e não meramente lógica do raciocínio analógico. Com o que pretende afirmar a necessidade - insuperável - de se recorrer, na comparação das duas intencionalidades problemáticas em confronto, a critérios especificamente jurídicos, por ele identificados como "critérios normativo-teleologicamente materiais" (cf. A. CASTANHEIRA Neves, Metodologia Jurídica, pág. 249).

"Os casos relevantes serão juridicamente análogos quando os seus respetivos e concretos sentidos problemático-jurídicos (...) se puderem pensar numa conexão justificada pela intenção fundamental de juridicidade que os constitui na sua especificidade jurídica (...). Mas essa analogia problemática não dispensa um segundo momento analógico de índole agora judicativa, pois só uma ponderação comparativa a nível judicativo poderá levar a concluir que a solução jurídica do caso-foro é normativo-juridicamente adequada também para o caso-tema" (cf. A. Castanheira Neves, Metodologia Jurídica, pág. 261).

Tudo isto a querer dizer que, em concreto, o juízo analógico - em que se consubstancia, afinal, toda a interpretação - apresenta um carácter axiológico-normativo, a implicar a intuição do próprio sentido do direito que, assim, se derrama em cada mobilização que se há-de fazer dos diversos critérios legais erigidos para a procedência de uma pretensão indemnizatória procedente. 
no hermenêutico de compreensão do sentido textual do artigo $72^{\circ}$ do (anterior) CAM.

A norma em questão deve ser compreendida na sua articulação com o princípio da autonomia privada e da liberdade estatutária que a este nível se reconhece. De facto, as associações têm vindo a ser entendidas como uma "manifestação civil básica da liberdade de associação", consagrada no artigo $46^{\circ} \mathrm{CRP}$, e tal liberdade de associação não pode ser reduzida à possibilidade de se constituir ou não uma associação. Consoante esclarece Menezes Cordeiro, "as referências constitucionais à liberdade de associação não se limitam a consagrar a possibilidade de livre constituição de pessoas coletivas e, maxime, de associações; elas estabelecem algumas regras importantes quanto à sua autonomia e ao seu funcionamento, com relevo direto na interpretação e na aplicação da lei civil" ${ }^{10}$. Entre tais regras, encontramos, exatamente, como refração daquela, a liberdade estatutária e a autonomia na condução dos destinos da pessoa coletiva.

É neste fundamento que encontramos a ratio da possibilidade de se disciplinar estatutariamente o voto por correspondência. Na remissão da norma para o princípio, haveremos de concluir pelo caráter dispositivo dela: ou seja, os estatutos podem não permitir o voto por correspondência ou podem estabelecer para eles regras diversas daquelas que resultam do artigo $72^{\circ} \mathrm{CAM}$.

Só assim não será se se descortinar um qualquer interesse que justifique a preterição do princípio. Resta, então, indagar em que medida existirá algum princípio que se oponha à possibilidade de se controlar a veracidade das assinaturas através de um procedimento que não passe pelo reconhecimento notarial das mesmas, ou se existirá algum interesse de ordem pública que justifique a imperatividade da solução legal quanto ao ponto ${ }^{11}$.

O reconhecimento notarial das assinaturas cumpre diversos objetivos. Aposta a um documento particular, pode configurar uma dada forma negocial, chamada a desempenhar determinadas funções, que justificam o afastamento da regra da liberdade de forma. Não cremos, porém, que qualquer dos objetivos prosseguidos com a imposição formal estejam aqui em causa. As razões determinativas da forma da declaração são claras: garantir a reflexão das partes no negócio; permitir uma formulação mais precisa e mais clara da vontade; publicitar o ato; separar a

9 A. Menezes Cordeiro, Tratado de Direito Civil Português, I, tomo III, Almedina, Coimbra, 2004, pág. 551. Veja-se, também, A. Menezes CordeIro, Tratado de Direito Civil, IV, Almedina, Coimbra, 2019, pág. 559

${ }^{10}$ A. Menezes Cordeiro, Tratado de Direito Civil Português, pág. 556.

${ }^{11}$ Equacionando nos mesmos moldes questões que rodeiam a dúvida acerca da imperatividade ou supletividade de normas que regem a vida das associações, cf. A.F. Morais ANTUNES, «O governo das associações civis», Direito das Associações - o controlo da legalidade, CEJ, 2018, págs. $110 \mathrm{~s}$. Da autora, cf., igualmente, A. F. Morais AnTUnEs, «O governo das associações civis», O Governo das Organizações: a vocação universal do Corporate Governance, Almedina, Coimbra, 2011, págs. 503-558 
negociação da efetiva celebração do negócio ${ }^{12}$. Simplesmente, nenhuma delas se torna operante quando se trata do voto por correspondência. Do que se trata é de garantir que a missiva contendo a declaração de voto foi efetivamente emitida por aquele que nela se identifica, evitando, assim, interferências de terceiros na formação da vontade da pessoa coletiva, por um lado, e, por outro lado, o afastamento do associado dessa tomada de posição coletiva. Repare-se, ademais, que mesmo o controlo de legalidade que se alcança por via da intervenção notarial - quando a forma exigida seja mais solene - deixa de estar em causa, dado que aquilo que se refere no artigo $72^{\circ} \mathrm{CAM}$ é, apenas, o reconhecimento das assinaturas.

Ora, existem outras formas de controlo para além do reconhecimento notarial das destas. E o artigo 44\% Estatutos do Montepio Geral parece acautelar o controlo da veracidade, ao dispor que «a assinatura do associado deve ser conferida com o espécime existente no Montepio Geral».

\section{A INTERPRETAÇÃO COMO UM PROBLEMA NORMATIVO (CONT.): A INTERPRETAÇÃO DOGMÁTICA E TELEOLÓGICA E O RECURSO AOS DADOS SISTEMÁTICOS - O REGIME DAS SOCIEDADES E DAS ASSOCIAÇÕES}

A interpretação do $\operatorname{artigo~} 72^{\circ}$ do anterior Código das Associações Mutualistas parece ser confirmada por uma leitura sistemática do ordenamento jurídico. Esta impõe-se com meridiana clareza. Com efeito, os objetivos da interpretação - outrora disputados entre as correntes subjetivistas e objetivistas - transmutam-se, fazendo dialogar a interpretação dogmática e a interpretação teleológica. A primeira não se diferencia totalmente da segunda, posto que o sistema tem uma intencionalidade problemática incontornável. E é por isso que, afastada que esteja a visão estrita dessa teleologia para a aceitarmos no sentido mais fundo de incorporação da própria teleonomologia, se há-de chegar a perceber que, se, de facto, a arquitetura sistemática em si mesma não garante a concludência do nosso discurso, posto que, viabilizando a delimitação da juridicidade a partir do sistema, poderia deixar sem resposta casos que reclamassem, pela pressuposição das exigências de sentido que entretecem a normatividade, uma resposta de direito, nem por isso podemos deixar de lado a consideração desse sistema, entendido, também ele, como um problema.

Aliás, de acordo com o ensinamento da doutrina, as regras atinentes às sociedades comerciais - mais completas do que as que disciplinam as associações -

\footnotetext{
${ }^{12}$ Cf. C. A. Mota Pinto, Teoria Geral do Direito Civil, $4^{a}$ edição, Coimbra Editora, Coimbra, 2005, págs. 428-429.
} 
levam ínsitos os valores fundamentais do direito privado ${ }^{13}$, razão pela qual podem ser aplicadas por analogia ${ }^{14}$. Recusando reservar a analogia para a resolução de casos omissos, a chamada à colação de determinadas regras que regulam as sociedades como expediente interpretativo que, entendido na sua intencionalidade problemática, pode auxiliar na busca de uma solução justa torna-se imperioso.

A este ensejo, são várias as normas a que podemos recorrer.

$\mathrm{O}$ artigo $247^{\circ} \mathrm{CSC}$, no tocante às sociedades por quotas, consagra que, «não havendo disposição de lei ou cláusula contratual que o proíba, é lícito aos sócios acordar, nos termos dos números seguintes, que a deliberação seja tomada por voto escrito». O voto escrito a que se refere o preceito é, conforme decorre dos seus restantes números, o voto por correspondência. De facto, só essa particularidade explica o disposto no $\mathrm{n}^{\circ} 4$, nos termos do qual, quando se proceder a votação por escrito, «o gerente enviará a todos os sócios a proposta concreta de deliberação, acompanhada pelos elementos necessários para a esclarecer, e fixará para o voto o prazo não inferior a dez dias».

Parece, portanto, não existir qualquer limitação ao voto por correspondência, não se impondo requisitos adicionais no tocante à certificação das assinaturas, no âmbito das sociedades por quotas. A única limitação à votação por escrito, que aqui compreendemos como votação por correspondência, é a que resulta do artigo $249^{\circ} \mathrm{CSC}$ e diz respeito à impossibilidade de, no tocante a essa forma de votação, existir representação do sócio.

Por seu turno, o artigo $384^{\circ} \mathrm{CSC}$ dispõe, a propósito das sociedades anónimas, que, «se os estatutos não proibirem o voto por correspondência, devem regular o seu exercício, estabelecendo, nomeadamente, a forma de verificar a autenticidade do voto e de assegurar, até ao momento da votação, a sua confidencialidade, e escolher entre uma das seguintes opções para o seu tratamento: a) determinar que os votos assim emitidos valham como votos negativos em relação a propostas de deliberação apresentadas ulteriormente à emissão do voto; b) autorizar a emissão de votos até ao máximo de cinco dias seguintes ao da realização da assembleia, caso em que o cômputo definitivo dos votos é feito até ao $8 .^{\circ}$ dia posterior ao da realização da assembleia e se assegura a divulgação imediata do resultado da votação».

\footnotetext{
${ }^{13}$ A. Menezes Cordeiro, Tratado de Direito Civil Português, pág. 566; e A. Menezes Cordeiro, Tratado de Direito Civil, pág. 578

Menezes Cordeiro tem vindo a reconhecer que, “à medida que se acentua o relevo económico, direto ou indireto, de associações e fundações, estas têm vindo a dotar-se de esquemas de acompanhamento, de consulta e de fiscalização semelhantes aos das sociedades" - A. Menezes CordeIro, Tratado de Direito Civil Português, pág. 548.

Entre nós, veja-se, ainda, A. F. Morais Antunes, "O governo das associações civis", Direito das Associações, pág. 114.

${ }^{14}$ Em sentido crítico, cf. D. RANOoux, «L'application subsidiaire du droit des sociétés aux associations/ Note sous Cour de cassation (1civ.) 3 mai 2006», Revue des Sociétés, 4 (2006), págs. 855-860.
} 
Aqui, prevê-se expressamente a possibilidade de voto por correspondência, remetendo-se para os estatutos a forma de verificação da autenticidade do mesmo. A diferença em relação ao que se consagra em matéria de sociedades por quotas percebe-se se atentarmos na estrutura societária de cada uma das modalidades de sociedade. Com efeito, enquanto as sociedades por quotas se caracterizam por uma maior concentração do capital social, dividido em quotas, as sociedades anónimas baseiam-se numa lógica de dispersão de capital, aproximando-se da impessoalidade do substrato de uma associação. Dito de uma forma mais direta, no quadro de uma sociedade por quotas, nas quais, por regra, o número de sócios é muito menor do que numa sociedade anónima e do que o número de associados de uma associação, parece perder sentido a necessidade de controlo da veracidade do voto, tanto mais que o voto por escrito implica que, previamente, o gerente enviará a todos os sócios a proposta de deliberação, acompanhada dos elementos necessários para a esclarecer, por carta registada.

Se não se pode vislumbrar a adequada analogia entre uma associação mutualista e uma sociedade por quotas, em termos estruturais, ela parece impor-se quando o confronto seja feito entre a primeira e uma sociedade anónima. Significa isto que, se é o próprio legislador que remete para os estatutos da sociedade a forma de controlo da veracidade do voto, não se divisam quaisquer razões para, ao nível de uma associação mutualista, o controlo ter de ser feito por um notário.

Uma associação mutualista é, como referido, uma pessoa coletiva de direito privado, de natureza associativa, com um número ilimitado de associados, fundos patrimoniais variáveis e duração indefinida que, essencialmente, através da entreajuda e da quotização dos seus associados, pratica, no interesse destes e das suas famílias e em obediência aos princípios mutualistas, fins de auxílio recíproco de proteção social e desenvolvimento humano. Conjuntamente com as cooperativas, estas pessoas coletivas constituem um dos pilares da economia social, dando eco ao princípio económico da reciprocidade ${ }^{15}$. Em causa estão, portanto, pessoas coletivas no âmbito das quais se procede à gestão de fundos comuns que resultam das quotizações dos associados, com vista a acautelar o seu futuro e das suas famílias $^{16}$.

Dentro das pessoas coletivas, qualificam-se como associações, pela ausência de fim lucrativo. Ainda que se possam dedicar a atividades económicas potenciadoras de lucros e possam gerá-los, sobretudo pela sua ligação às caixas económicas, a finalidade das associações mutualistas não é a sua distribuição pelos

\footnotetext{
15 Autores há que integram nos pilares da economia social as associações em geral e as fundações. Cf., nesse sentido, R. SEQUeIRA, Associações mutualistas em Portugal: aspetos históricos e prospetivos, Lisboa, ISCTE, 2017, pág. 1. Acerca do princípio da reciprocidade, vejam-se, na obra citada, as págs. 19 e segs.

${ }^{16}$ R. SequeIra, Associações mutualista em Portugal, pág. 39.
} 
associados, mas sim a garantia do futuro, ou de algumas dimensões do futuro, dos seus membros e respetivas famílias ${ }^{17}$.

A lógica subjacente à associação mutualista é a da solidariedade entre todos os seus membros, recuperando-se, de certo modo, a ideia de que «o que é meu é teu» ${ }^{18}$. E se a entreajuda é a palavra de ordem, então compreende-se que a gestão da pessoa coletiva se deva basear na perfeita igualdade de todos os que integram o seu substrato, independentemente do capital detido ou da quota titulada. Um homem vale um voto, conforme, aliás, explicita o artigo $11^{\circ} \mathrm{CAM}^{19}$.

$\mathrm{O}$ dado afasta as associações mutualistas das sociedades, assumam elas a forma de sociedades por quotas ou de sociedades anónimas. Mas, não obsta a que determinadas regras atinentes ao governo da pessoa coletiva não possam ser mobilizadas, sobretudo tendo em conta outros elementos de aproximação entre elas.

Entre esses fatores de aproximação encontram-se o número ilimitado de associados e o caráter anónimo dos sócios de uma sociedade anónima; a possibilidade de as associações mutualistas desenvolverem atividades que se inserem, tipicamente, no objeto de uma sociedade comercial. Pense-se, por exemplo, na possibilidade de as associações mutualistas titularem caixas económicas ${ }^{20}$. Por outro lado, importa não esquecer, como explicita Paulo Linhares Dias, que, "sendo certo que os produtos mutualistas, sobretudo destinados à complementaridade da reforma e proteção social, se baseavam na solidariedade e da redistribuição da riqueza, na verdade, e numa visão simplista, as mutualidades partiam da quotização dos associados, dos fundos com que contribuíam e da capitalização gerada pela aplicação desses fundos e de fundos próprios, para satisfazerem os seus encargos e garantirem os regimes prestacionais com os seus associados, aliás, ainda é esta a fórmula prevista na lei”, “(...) a evolução do mundo da finança alterou estes padrões, procurando-se a maior rentabilização das aplicações através de produtos cada vez mais sofisticados, e que se vieram a revelar pouco seguros" 21 e que apresentam uma similitude bastante com muitos produtos financeiros.

Significa isto que nos deparamos com uma similitude (que não identidade) material e estrutural entre as associações mutualistas e muitas sociedades comerciais. Materialmente, denota-se uma aproximação entre a atividade levada a cabo por uma

\footnotetext{
${ }^{17}$ R. Sequeira, Associações mutualista em Portugal, pág. 38.

${ }^{18}$ Cf. R. Sequeira, Associações mutualista em Portugal, pág. 37, recordando as palavras de Vítor Melícias, na apresentação de um livro sobre mutualismo.

${ }^{19}$ Sobre o ponto, cf. R. Sequeira, Associações mutualista em Portugal, pág. 46.

${ }^{20}$ Esta particularidade, aliás, levanta problemas jurídicos muito interessantes, atinentes aos modelos de supervisão. Sobre o ponto, cf. P. LINHARES DiAs, A supervisão da atividade financeira no terceiro setor. $O$ caso das associações mutualistas, Coimbra, CEDIPRE, 2018. Note-se que o novo Código das Associações Mutualistas vem dar uma resposta a este interessante problema.

${ }^{21}$ P. Linhares Dias, A supervisão da atividade financeira no terceiro setor. $O$ caso das associações mutualistas, pág. 11.
} 
e outra pessoa coletiva. Estruturalmente, o caráter anónimo do substrato que as integram (quando pensamos nas sociedades anónimas) permite um juízo de similitude.

É claro que subjacente à similitude que se aponta há diferenças inultrapassáveis: a intencionalidade que preside ao mutualismo afasta-o das pessoas coletivas cujo escopo seja o lucro. Acontece que esta particularidade - relevantíssima, diga-se não preside à exigência de controlo da veracidade do voto por correspondência. $\mathrm{Na}$ verdade, tal exigência prende-se com a necessidade de garantir que cada associado possa, efetivamente, contribuir para a formação da vontade da pessoa coletiva, enquanto centro autónomo de imputação de relações jurídicas. Ora, a mesmíssima preocupação existe no tocante às sociedades: não é o facto de o montante do capital subscrito determinar um maior ou menor número de votos que justifica um maior risco de desvirtuar aquela vontade que se pretende formada de um modo são e, portanto, sem interferências de terceiros estranhos ao substrato da pessoa coletiva.

Acresce que, a partir do momento em que se admite a possibilidade de representação nas assembleias gerais das associações, sem que a procuração habilitante tenha de revestir qualquer forma especial, parece cair por terra qualquer argumento no sentido da necessidade de controlo específico da autenticidade do voto do associado mutualista ${ }^{22}$.

O problema da representação dos associados nas assembleias gerais das associações tem suscitado dúvidas na doutrina e na jurisprudência, em face do disposto no artigo $180^{\circ} \mathrm{C}$. Civ., nos termos do qual, "salvo disposição estatutária em contrário, a qualidade de associado não é transmissível, quer por ato entre vivos, quer por sucessão; o associado não pode incumbir outrem de exercer os seus direitos pessoais". As dúvidas adensam-se em face do artigo $175^{\circ} \mathrm{C}$. Civ., atenta a formulação do seu ${ }^{\circ} 1$, a parecer exigir a presença física dos associados na referida assembleia ${ }^{23}$. De acordo com a jurisprudência do STJ, exigir-se-ia a presença dos associados no caso dos números 1 a 3 do artigo $175^{\circ}$, embora já não em caso de deliberação sobre a dissolução ou prorrogação da pessoa coletiva, por questões práticas, atinentes à inviabilidade de, de outra forma, estas assembleias se realizarem ${ }^{24}$.

\footnotetext{
${ }^{22}$ Sobre o ponto, cf. L.CARVAlho Fernandes, «A representação dos associados nas assembleias gerais das associações», Centenário do nascimento do Professor Doutor Paulo Cunha: estudos em homenagem, Coimbra, Almedina, 2012, págs. 641-660

${ }^{23}$ A. F. Morais Antunes, “O governo das associações civis”, Direito das Associações, pág. 114; L. Carvalho Fernandes, Teoria Geral do Direito Civil, I, $6^{a}$ edição, Lisboa, UCE, 2012, pág. 622; A. Menezes Cordeiro, Tratado de direito civil português, pág. 684; A. Menezes Cordeiro, Tratado de direito civil, pág. 698; J. Oliveira Ascensão, Direito Civil/Teoria Geral, I, $2^{\circ}$ edição, Coimbra Editora, Coimbra, 2000, pág. 300; P. HenriQues, "O regime geral das associações", Direito das Associações - o controlo da legalidade, CEJ, 2018, págs. $163 \mathrm{~s}$.

${ }^{24}$ Cf. Ac. STJ 16 de Abril de 2009, Proc. nº 09B0139 (relator Lázaro Faria)

Veja-se, porém, em sentido contrário o Ac. STJ 16 de Novembro de 2006, Proc. nº6B2647, relator João Bernardo.
} 
Não cremos, porém, que esta posição possa ser sufragada. Desde logo, os argumentos avançados para a sustentar padecem da fragilidade de uma interpretação literal, que perde inclusivamente sentido lógico. Como sublinha Filipa Morais Antunes, "com base num argumento de coerência, não se compreende à luz da finalidade alegadamente visada pela norma - a proteção do carácter predominantemente coletivo dos interesses tutelados - que, para a tomada de deliberações relevantes para a associação, o legislador tenha sido menos exigente, ao admitir, quanto a estas, o voto por procuração e ao não exigir a presença física dos associados" 25 . Dito de outro modo, qual o sentido de se exigir a presença física dos associados para as deliberações relativas à alteração dos estatutos (nas quais se impõe uma maioria qualificada), justificada pela importância das mesmas, e prescindir-se dela quando em causa esteja a decisão acerca da continuidade ou não da pessoa coletiva? A mesma razão de operacionalidade prática não poderá estar presente no tocante a estas últimas?

Por outro lado, o caráter predominantemente coletivo dos interesses tutelados não é posto em causa com a possibilidade de representação; muito menos se poderá dizer que se perde a natureza coletiva da decisão. É que na representação e pela representação é ainda e sempre a vontade do representado que se torna atuante.

Não só o argumento literal retirado do artigo $175^{\circ} \mathrm{C}$. Civ. não colhe, como podemos aduzir outros argumentos de sinal contrário ${ }^{26}$. Em primeiro lugar, consoante a doutrina tem vindo a sublinhar, na parte final do artigo $180^{\circ} \mathrm{C}$. Civ., não se integra o direito de voto: o mesmo é dizer que o direito de voto não é um dos direitos pessoais titulados pelo associado ${ }^{27}$. Em segundo lugar, a considerar-se correta a visão restritiva acerca do problema da representação, perderia sentido o artigo $176^{\circ} / 1 \mathrm{C}$. Civ. ${ }^{28}$, ao determinar que "o associado não pode votar, por si ou

\footnotetext{
${ }^{25}$ A. F. Morais Antunes, "O governo das associações civis”, Direito das Associações, pág. 118.

${ }^{26}$ Nesse sentido, cf. A. F. Morais Antunes, "O governo das associações civis", Direito das Associações, pág. 119.

${ }^{27}$ Nas palavras de Paulo Henriques, "a ideia de incluir o direito de voto no âmbito da proibição da segunda parte do artigo $180 .^{\circ}$, isto é, no leque dos direitos que o associado não pode incumbir outrem de exercer, está em manifesta contradição com a própria lei. Na verdade, em vista do que estabelece o artigo $176 .^{\circ}$, n. ${ }^{\circ}$, é seguro que o Código Civil admite que o associado incumba outrem de votar por ele; apenas se discute o âmbito de aplicação da norma: se é geral ou se vale apenas para os casos de dissolução e prorrogação. E nem nos devemos surpreender que o direito de voto numa associação admita exercício por procuração: são opções de funcionalidade que significam uma ampliação da liberdade de participação" - cf. P. HENRIQUES, «O regime geral das associações», pág. 163. Cf., também, A. F. Morais Antunes, «O governo das associações civis», Direito das Associações, pág. 119; Menezes Cordeiro, Tratado de direito civil português, pág. 684; A. Menezes Cordeiro, Tratado de direito civil, pág. 694; J. Oliveira Ascensão, Direito Civil/Teoria Geral, pág. 300.
}

${ }^{28}$ Cf. M. Caetano, «As Pessoas Colectivas no Novo Código Civil Português», O Direito, 99 (1967), pág. 108, considerando que o artigo $176^{\circ}$ apenas diria respeito às deliberações que, nos termos do artigo $175^{\circ}$, pudessem ser tomadas por voto por procuração. Criticando a solução, cf. P. HenRIQUEs, «O regime geral das associações», pág. 163, afirmando que, "ao confinar a aplicação do disposto no 
como representante de outrem, nas matérias em que haja conflito de interesses entre a associação e ele, seu cônjuge, ascendentes ou descendentes"29.

A admissibilidade de voto por meio de representante está, aliás, expressamente, prevista no caso das sociedades, nos artigos $189^{\circ} / 4,249^{\circ}$ e $380^{\circ} \mathrm{CSC}$.

Os argumentos que se mobilizam no sentido da admissibilidade do voto por procuração nas assembleias gerais das associações são transponíveis para as associações mutualistas. $\mathrm{O}$ paralelo entre o que se disse e o que resulta dos artigos $85^{\circ}$ e $86^{\circ}$ CAM é evidente.

A partir do momento em que se admite o voto por procuração, haveremos de considerar que esta não está - de acordo com o artigo $262^{\circ} / 2 \mathrm{C}$. Civ. - sujeita a qualquer formalidade especial. O princípio geral da liberdade de forma, acolhido expressamente pelo legislador em matéria de representação voluntária, só é afastado em duas hipóteses: a) ou quando uma norma especificamente determine uma forma (condicionando a própria representação, como ocorre em sede de sociedades comerciais), ou b) quando o negócio que com base nos poderes por ela atribuídos vá ser celebrado pelo representante esteja submetido a uma dada formalidade. Não sendo esse o caso de um voto numa assembleia geral, afasta-se a exigência de qualquer controlo de legalidade por parte de uma entidade cuja atuação faça fé pública, como um notário. E se os órgãos da pessoa coletiva podem exigir que o representante faça prova dos seus poderes, designadamente através da apresentação de um documento onde tais poderes representativos constem, nos termos do artigo $260^{\circ} \mathrm{C}$. Civ., tal exigência está longe da necessidade de outorga de uma escritura pública ou do reconhecimento notarial das assinaturas. Ora, se o risco de interferência abusiva de um terceiro existe nestas hipóteses, não se percebe por que razão ela tem de ser totalmente afastada na situação de voto por correspondência.

Donde se deve concluir que, ainda que o legislador se tenha mostrado particularmente cauteloso, cabe aos estatutos da associação mutualista a última palavra em matéria de procedimentos de verificação da autenticidade da assinatura no voto por correspondência. A liberdade que subjaz à associação - à sua constituição, ao seu funcionamento e à participação de cada um dos associados - determina ser esta a melhor solução. Nas palavras de Paulo Henriques, "a liberdade de organização e regulamentação interna deve ser concretizada, desde logo, numa ampla liberdade de modelação do conteúdo dos estatutos" ${ }^{30}$. De igual modo, o princípio democrático depõe no mesmo sentido.

artigo $176 .^{\circ},{ }^{\circ}{ }^{\circ}$, aos casos em que o assunto a deliberar é a dissolução ou a prorrogação, o intérprete chega a resultados irrazoáveis: a ser assim, o associado poderia votar, por si, mesmo havendo o conflito de interesses, em todas as outras matérias".

${ }^{29}$ Cf. P. Henriques, «O regime geral das associações», pág. 296

${ }^{30} \mathrm{P}$. Henriques, «O regime geral das associações», pág. $164 \mathrm{~s}$. 
Tudo visto, podemos concluir que os dados sistemáticos fortalecem a interpretação da norma (do artigo $72^{\circ} \mathrm{CAM}$ ) a que se acedia por via da sua remissão para os princípios.

\section{O NOVO CÓDIGO DAS ASSOCIAÇÕES MUTUALISTAS E O REFORÇO DA POSIÇÃO SUSTENTADA}

O novo Código das Associações Mutualistas especifica, no seu preâmbulo, que se impõe o "fortalecimento do caráter democrático e da participação dos associados", para o que se introduzem "normas que possibilitam ou impõem uma participação mais alargada dos associados e o controlo mais efetivo da sua participação". Nos termos do artigo 86\% $/ 4$ do novo CAM, "salvo se os estatutos dispuserem de outra forma, é admitido o voto por correspondência, sob condição de o seu sentido ser expressamente indicado em relação ao ponto ou pontos da ordem de trabalhos, ser assegurada a sua autenticidade, nomeadamente através de reconhecimento da assinatura nos termos legais e garantida a sua confidencialidade, devendo ainda observar-se os demais requisitos exigidos pelos estatutos". O reconhecimento das assinaturas nos termos legais é agora assumido como um meio, entre outros possíveis, de assegurar a autenticidade do voto.

Embora a lei nova não sirva para interpretar a lei antiga, sempre se haverá de reconhecer que, ao presidir à nova disciplina a mesma intencionalidade que contaminava o anterior regime, não estaremos perante uma inovação por parte do legislador, mas diante do esclarecimento necessário de uma questão, cuja solução, apesar da controvérsia, se afirmava com meridiana clareza.

\section{Conclusão}

O Tribunal da Relação de Lisboa considerou que o artigo $72^{\circ}$ do anterior CAM configurava uma norma dispositiva, permitindo que os Estatutos de uma associação mutualista estabelecessem um procedimento de verificação de assinaturas, no voto por correspondência, que não passasse pelo reconhecimento notarial daquelas.

A adequada interpretação da norma, segundo os cânones metodológicos mais consentâneos com o verdadeiro sentido da realização do direito, a remetê-la para os princípios normativos, confirma o juízo decisório. Em abono desta posição concorrem ainda outros argumentos, a chamar à colação algumas das regras de governo das associações em geral e das sociedades comerciais.

A norma deve, portanto, ser entendida como uma refração do princípio da liberdade de associação e estatutária. E o artigo 86\% $/ 4$ do novo CAM vem, de uma forma mais explícita, consagrar essa solução. 


\section{Bibliografia}

Antunes, A.F. Morais, «O governo das associações civis», Direito das Associações - o controlo da legalidade, CEJ, 2018, págs. $110 \mathrm{~s}$.

Antunes, A. F. Morais, «O governo das associações civis», O Governo das Organizações: a vocação universal do Corporate Governance, Almedina, Coimbra, 2011, págs. 503-558.

Ascensão, J. Oliveira Direito Civil/Teoria Geral, I, $2^{\circ}$ edição, Coimbra Editora, Coimbra, 2000

Barbosa, Mafalda Miranda / Rodrigues, João Pedro, «Da incompetência do TC para apreciar eventuais violações do princípio da legalidade criminal: breve reposicionamento crítico em sede metodológica», Estudos em homenagem ao Prof. Doutor António Castanheira Neves, vol. III, Coimbra Editora, Coimbra, 2008, págs. 108 s.

Bronze, J. Pinto, Lições de Introdução ao Direito, Coimbra Editora, Coimbra, 2002.

Cordeiro, A. Menezes Tratado de Direito Civil Português, I, tomo III, Almedina, Coimbra, 2004.

Cordeiro, A. Menezes, Tratado de Direito Civil IV, Almedina, Coimbra, 2019.

Dias, P. Linhares A supervisão da atividade financeira no terceiro setor. $O$ caso das associações mutualistas, Coimbra, CEDIPRE, 2018.

Fernandes, L. Carvalho, «A representação dos associados nas assembleias gerais das associações», Centenário do nascimento do Professor Doutor Paulo Cunha: estudos em homenagem, Coimbra, Almedina, 2012, págs. 641-660.

Fernandes, L. Carvalho, Teoria Geral do Direito Civil, I, 6a edição, Lisboa, UCE, 2012.

Henriques, P., "O regime geral das associações", Direito das Associações - o controlo da legalidade, CEJ, 2018, págs. $158 \mathrm{~s}$.

Neves, A. Castanheira, Metodologia Jurídica - Problemas fundamentais, Coimbra Editora, Coimbra, 1993.

Neves, A. Castanheira, «Interpretação Jurídica», Digesta, vol. II, Coimbra Editora, Coimbra, 1995.

Neves, A. Castanheira, O actual problema metodológico da interpretação jurídica, I, Coimbra Editora, Coimbra, 2003.

Ranooux, D., «L'application subsidiaire du droit des sociétés aux associations/ Note sous Cour de cassation (1civ.) 3 mai 2006», Revue des Sociétés, 4 (2006), págs. 855-860.

SequeIra, R., Associações mutualistas em Portugal: aspetos históricos e prospetivos, Lisboa, ISCTE, 2017. 